\title{
A Review of Parents' Opinions and Legislation Concerning TV Advertising to Children in Buruburu, Nairobi, Kenya
}

\author{
Rose Achieng Oduho \\ Maseno University, P. O. Box 333 - 40105, Maseno, Kenya;
}

\begin{abstract}
This paper undertakes a review of parents' opinions on the influence of TV advertising to children based on a study conducted in Buruburu estate in Nairobi, Kenya. For the purpose of collecting data, the author selected Buruburu estate because it is one of the oldest middle-class estates whose residents show general characteristics associated with the class. The model of survey research was used in answering research questions. The sample population comprised of parents of children aged between 6 and 13 years, exposed to TV advertising. A total of 70 children from Buruburu estate were interviewed. Thirty-five children in the sample were between ages 6 and 9 years. The sampling method used in selecting samples for interviews was the stratified random sampling technique. Two techniques of discussions were used to source data from the respondents. They included the use of interview guides and focus group discussions as a supporting method. Data from the field was coded carefully to ensure a high degree of accuracy and consistency. Coding was followed by frequency counts of data from which tables and other graphic representations were generated. The study findings revealed that that middle-class parents in Buruburu are generally aware of the harms that TV advertising could have on their children. Indeed, parents should begin to take an active role in enlightening their children on adverts. This would help minimise some of the possible negative influences by making children understand the purpose and intentions of adverts. Although TV advertising has negative influence it does have a beneficial side for example it gives information on a product and demonstrates its use. The positive side of TV advertising on children was not discussed in the report because it was beyond the scope of this study. In general, it is recommended that advertising policies should stress social marketing rather than commercial advertising on television. The significance of the study is important for media practitioners and parents in that they will have a clearer understanding of the impact of TV advertising on children and take necessary steps towards curbing the problem.
\end{abstract}

Keywords: Parents, TV Advertising, Children, Buruburu, Nairobi, Kenya

\section{Introduction}

Arens and Bovee [1] define advertising as a way of capturing and maintaining consumer markets for the purpose of sales. Space or time for an advertising message generally must be bought. Advertisers commonly target particular audiences and effort is put in the creation of advertisements in order to communicate efficiently. This helps in maintaining brand loyalty and informs consumers on product's latest features. This supports Aristotle's view that: advertising is made of artistic and non-artistic proofs and it's a conscious attempt to modify thought and action. Advertising is therefore done by manipulating motive towards predetermined ends (ibid.). A predetermined end probably means convincing the consumer to behave in a predicted manner, which is purchasing an advertised product.

Ingman [2] notes that television advertising begun as a form of public service announcement. It also served the purpose of channelling the distribution of goods, relieving regional shortages as well as surpluses. It was in September 1955 that the United Kingdom broadcast its first television commercial. This came as a result of the Beveridge Committee coming together and agreeing that advertising was necessary. This was because it would serve as a source of revenue for the British Broadcasting Corporation. There were no precise rules then as to how TV advertising was to be conducted. But there was time restriction on the amount of time to be allocated to TV advertising. The amount of time given to advertising within programmes was very limited then. This was so as not to detract from the main aim of programmes, which is to entertain, instruct and inform.

Later the British government appointed three advisory committees to handle TV advertising matters. The committees comprised three distinct groups which would address TV advertising and religious matters, TV advertising and children's welfare, and advertising plus standards of conduct. This saw TV advertising being permitted to operate under two distinct advertising systems. They included the Sponsorship and the Spot system. In sponsorship, an advertiser was allowed to buy large a section of time, e.g. 1 hour or 30 minutes, within which they would air a programme under their company's brand name. The high cost of producing TV programmes or sponsoring them gave rise to the use of spots. In this case, independent advertisements were inserted in between or within programmes produced by networks. 
In Kenya today, advertising is a major industry that operates within the spheres of formal economy. In the past years advertising has grown rapidly along other areas like marketing. During the last four decades the number of advertising agencies (organisations that plan, create, and prepare client's advertising campaigns and promotional materials) have grown from 3 in 1963 to 10 by the beginning of 2005 [3]. Most advertising agencies started their operations in Kenya in the mid-seventies, between 1973 and 1977. Many of these registered agencies are subsidiaries of multinational agencies based in United Kingdom and USA. There are only two types of advertising agencies in Kenya, namely the full service agency and the creative boutique. Full service agencies offer all advertising services while creative boutique offers selected services. Over $80 \%$ of the advertising agencies by 1983 were receiving media commission as a popular method by which they were being compensated. Agencies source their clients through personal contacts/solicitation, and speculative presentation to prospective clients [4].

Among the indigenous agencies that are 100\% Kenya owned is one known as Spellman and Walker. It is a full service agency that handles creation of TV adverts done by its creative service department. Their greatest strength is in quality productions, strategic securing sites for their clients and having latest advertising equipment which they hire out to other advertising companies. Their major form of payment is media commission and they source clientele through referrals and advertising themselves. The Marketing Society of Kenya [3] estimates that on average an indigenous agency may handle more than Ksh80 million worth of business per year. Advertising agencies have greatly benefited from the growth of advertising, and have acted as the bridge between advertisers and TV stations. Mutiso [5] posits that media (organisations that sell time for the electronic media and space in print media so as to carry the advertiser's message to the target audience) houses have been depending a great deal on advertising. This has resulted in forms of media (TV) being subject to the needs of giant companies such as alcohol manufacturing industries, among others. Advertising in Kenya is no longer a job for the amateurs or a form of subsidy. It is a highly developed and sophisticated institution that is the centre of economic life of, newspapers and broadcasting stations.

The significance of advertising to the media is reflected in the dependence of media houses on advertising for their survival. This is clearly demonstrated in the fact that some media house productions have had to stop because advertisers were not placing advertisements [6]. For instance, Nairobi Times had to cease production for the same reason. Most media houses would collapse if advertising was withdrawn. This is because it provides the bulk of their revenue. Some economists argue that media are in the real sense not just a part of the economy, but its servant [7].

Media has a mysterious power of converting its audience into markets for the advertiser. For example, if one were to divide TV content into news and programmes it would be approximately $30 \%$ news and $70 \%$ programmes. The $30 \%$ can be assumed to serve the purpose of catching an audience attention for the advertisers. The $70 \%$ could probably be to keep the audience within for the purpose of presenting advertisements to them. The programmes keep the audience viewing as adverts are aired frequently until they get persuaded enough to purchase the product being advertised. Probably that is why advertisers targeting children present their adverts within programmes that attract them for example cartoon programs. Mutiso [5] supports this observation noting that $50 \%$ of the advertising agencies in Kenya determine their audience by the number of children expected to watch a programme. They make sure that to reach children they do proper timing and increase the frequency of their advertising campaigns. From these findings, it is evident that advertisers deliberately target children and use $\mathrm{TV}$ as the most appropriate media in reaching them.

\subsection{Advertising Regulations and Policies}

Advertising in Kenya is carried out within a regulatory framework. The framework helps to curb abuse and make advertising responsive to the public consensus as well as to the law. There are mainly two types of regulatory measures used in governing advertising. They include voluntary regulatory measures and legal regulatory measures. They both have different strengths and weaknesses, as indicated in their characteristics below, and best govern advertising when used together because they complement one another.

\subsubsection{Characteristics of Legislation}

a) These are written regulations; an advertiser should obey in public interest, under penalty of fine or imprisonment if proved guilty of an offence.

b) They depend on the interpretation of courts and may not be effective until a test case has occurred to set precedents.

c) They are to be evoked either by the plaintiff suing or by the crown deciding to prosecute.

\subsubsection{Characteristics of Voluntary Control}

They are different from those that apply to legal controls. 
1. These are written recommendations an advertiser should obey in public interest. An offending advertising agent risks losing her recognition status and right to commission. While the client risks damaging her reputation if a complaint is made to the Advertising Standards Board of Kenya (ASBK). This is a body under the MSK and was formed in the year 2003 to regulate advertising by setting standards.

2. They have no penalties as opposed to legislations and can only demand that an advertiser amend or withdraw an offending advertisement. Voluntary controls have no power to impose fine on offenders.

3. Voluntary controls are self-regulatory and are likely to prevent unethical advertising from appearing.

There are two kinds of legislations. Firstly, there is the common law, which is unwritten and largely based on precedent or what has been decided previously. Secondly, there is statute law in which the rules and penalties are set out in Acts (a bill passed by parliament and so placed on the statute book) [8]. In Kenya at present there exist no laws governing advertising published as Acts or bills (Confirmed by the Legal Advisor Nation Media Group and the Kenya Film Censorship Board). So the advertising sector has been operating without any advertising laws since 1963 . Voluntary measures have been in place since 1992 when MSK compiled a Code of ethics for advertisers. The government is making efforts to come up with laws that will govern advertising in future. In response parliament has proposed a bill to control Kenya's advertising [9]. These laws are yet to be drafted and tabled in parliament, which might take a considerable amount of time before they are enacted.

\subsubsection{Control of Advertising towards Children}

In a country like the USA, the Federal Trade Commission has the legal powers to act against advertising if there is evidence of injury to the public. It was established in 1914 and is an independent government regulatory agency. It is also charged with ensuring free and fair competition among the nation's business. In 1938, it was given powers to protect consumers of which special attention was given to children and the elderly. This is because the two groups were considered as vulnerable to advertising. Advertising claims that tend to exploit this group of people are considered unfair and against the advertising legal laws and regulations. FTC reviews adverts before they are run, and gives advance clearance in an advisory opinion. It publishes industry guides and trade regulation rules, which provide advertisers, agencies and the media with on-going information about its regulations. It is therefore the major regulator of USA's national advertising for products sold in interstate commerce [10].

In Kenya, there are regulations and policies that guard against negative impact of television advertising on children. An advertiser has an obligation to obey these regulations in public interest. It has a penalty of a fine or imprisonment attached to it. For instance, attention is drawn to Children's Act No. 8 of 2001 and Employment Act Chapter 226, the Laws of Kenya. There are also voluntary controls preventing unethical advertising. An existing voluntary control code is the Marketing Society of Kenya's Advertising Code of practice (1992). It gives general rules in advertising practice that include moral issues common amidst all media communication channels. It also gives guiding principles and recommended complaints procedures.

The Advertising Standards Board of Kenya (ASBK) is an independent body set up by the marketing and advertising industry to ensure that its system of self-regulation works. It is an arm of the MSK that ensures marketing principal activities do not work against the public interest. Marketing Society of Kenya (MSK) has a code of ethics for advertisers and advertising agencies in which it is clearly spelled out in Section 21.2.1 as follows:

Advertisements addressed to or targeting children or likely to influence them, should not contain any statements or visual presentations which might result in harming them visually, morally, physically or emotionally (Code of Advertising Practice and Direct Marketing, 2003).

The code recognizes children to include the youth (Advertising Standards 2003). The MSK code might be exhaustive in its do's and don'ts but because it is not specific it allows for almost any interpretation. Due to this weakness some adverts that do not adhere to the stipulated code, have managed to obtain clearance to be aired. MSK has not been endowed with powers to impose fines or punishment on offenders. This implies that if an advertiser does not comply with a stated requirement, very little can be done to legally apprehend them.

The Communications Commission of Kenya (CCK) is a government body formed in 1999 by an act of Parliament. Its main task is to issue licenses and frequencies to television and radio stations. It regulates the telecommunication sector but does not have control over any advertising content aired. Kariuki [11] reports that a Bill to control media ownership and to give legal authority to the Communication Commission of Kenya (CCK), as the independent regulatory authority, to oversee all aspects of the electronic media, was to be tabled in parliament in November 2001. Significantly, the Bill would give the CCK power to regulate the content of TV programmes. he proposed bill will at the same time control the amount of foreign content in advertising commercial on television. Unlike CCK whose powers are limited, Belch [10] indicates that America's Federal Communications Commission (FCC) maintains authority over advertising. It has powers to license and revoke from all broadcast stations. This was done in case they do not comply with advertising laws and regulations. 
FCC was formed by a communication act of parliament in 1934. It has jurisdiction over radio, television, telephone and telegraph industries.

Currently, policies governing TV advertising targeting children in Kenya are vague or do not exist. There is no proper body to enforce voluntary advertising policies or any policy specifically addressing children as a special group. There is need to develop such policies and to take into account children's special needs. However, in the absence of legal policies the Kenya government can use the United Nations Convention on the rights of a child as a guide to create policies protecting children. As an international treaty, it defines the rights of children in today's world. By the end of 1997, 191 countries had ratified the Convention on the Rights of the Child. The purpose is of this document to define principles that guide political decision-making on issues affecting children. One of its principles that deal with children and media is found in article 17 of the document and it states:

States Parties recognize the important function performed by the mass media and shall ensure that the child has access to information and material from a diversity of National and international sources, especially those aimed at the promotion of his or her social, spiritual and moral well-being, physical and mental health. To this end State Parties shall:

1. Encourage the mass media to disseminate information and material of social and cultural benefit to the child

2. Encourage international co-operation in the production, exchange and dissemination of such information and material from a diversity of cultural, national and international sources

3. Encourage the production and dissemination of children's books

4. Encourage the mass media to have particular regard to the linguistic needs of the child who belongs to a minority group or who is indigenous

5. Encourage the development of appropriate guidelines for the protection of the child from information and material injurious to his or her well being [12].

The stated convention guidelines are too general hence vague. Instead of offering precise methods of implementation, it makes the guidelines subject to a variety of objectives and interpretations. The guideline's only clear objective is to protect the child but does not state how. The guidelines would depend on how each country interprets them to fit in its laws. Interpretations can also be influenced by public interests and morals. According to the Convention on the rights of children article 32 states that:

Parties recognize the right of the child to be protected from economic exploitation and from performing any work that is likely to be hazardous or to interfere with the child's education or to be harmful to the child's health, mental, spiritual, moral, or social development [12].

This clause generally guards against negative TV content, though it does not specifically address the problem of TV advertising and children. Some of the advertising activities parents expose their children to as work, could be modelling for advertising agencies that could be generally summed up as child labour. The particular clause should be elaborated further so as to include advertising as child exploitation for commercial purposes.

Carlson and Feilitezen [13] emphasize that parents, guardians, State organs and social organizations should help in protecting the child against the harmful influence of mass media. Mass media in this case refers to television, radio, film, printed materials and exhibitions whose content may exert harm on a child's mental and moral development. Yet if the government becomes strict on privately owned media, they risk losing the revenue they collect from these media houses.

Article 18 of the Convention goes on to express the active role of a parent/guardian in the upbringing and development of a child, which the state should support except in special cases where it dictates on the upbringing in the best interest of the child. This suggests that parent's/guardian's efforts in protecting children against harmful influences of TV and other media should be supported by the state. Carlson and Feilitezen [13] further argue that: the UN Convention does not take note of the contradiction between children's access to information and measures to protect them from negative influences of the media. The policies on media influence, needs to include a broader perspective on how children now spend their day. The fact that most children spend many hours on television viewing including adverts than in school or with parents should make this matter urgent. This TV viewing habit in children raises a number of fundamental questions that have not been addressed in several countries, Kenya being one of them. To begin with, there is very little research/information on the topic of children and TV advertising in Kenya. Secondly, policy makers and TV advertisers are probably aware of children as vocalized by the UN but have done very little to address children's issues touching on media.

\subsubsection{Reasons for and against Advertising Legislation}

Feiltzen and Butch [14] note that some people feel advertising to children is not harmful at all and therefore there is no need for policies to govern TV advertising. They argue that self-regulation is effective and 
the advertising industry is taking sufficient responsibility for children. Regulation is done through the current self-regulation and existing codes of conduct. They also feel that the money raised from advertising is used in producing good programmes for children. Without advertising there would not be any quality programs for children. They reason that children are not as naïve and as gullible as most people assume. They can reason out and are usually able to tell what is right from wrong and so would not be influenced by TV advertising. Feiltzen and Butch [14] further indicate that since advertising is part of life, children ought to learn to deal with it. This is because they cannot be kept cocooned from the outside world-commercial messages. Television advertising is therefore good for them because it informs and educates on how the world operates. If advertising to children is banned consequences would be less choice, less innovation and higher prices.

Those who oppose TV advertising directed to children argue that this group cannot distinguish adverts from editorial programs and so have no ability to understand the purposes of TV advertising. Since childhood is a period of learning, children take all that they see or hear and believe in order to learn. For this reason, advertisers should not exploit this indispensable credulity for commercial gain. Since self-regulation has shown to be an insufficient means of protecting children from TV advertising, a more restrictive legislation is therefore needed. This would compensate for the weaknesses displayed by self-regulatory measures and effectively control advertising targeted at children [13].

\subsection{Problem Statement}

Television advertising may have an impact on children that could be desirable or undesirable. This research highlights the influences TV advertising has on urban middle class children in Nairobi. The impact can be noted on their behaviour, attitude and values. Ingman [2] notes that after sleeping an average child spends more time watching TV than in any other single activity. For many children today, reading is still not a second nature, whereas just looking and listening are. They tend to absorb more information from TV that they would not pursue in printed matter. This makes TV an important medium worth studying because through it children get to learn certain behaviours, attitudes and values that are not taught.

Some of the information could be detrimental to their physical, social and mental health. For example, research has shown that child-directed adverts for healthy foods can lose their effectiveness when children view advertisements for snack foods in the same sitting. Researchers speculate that advertising of adverts sugary cereals; candy and fast-food restaurants may be contributing to the increase in childhood obesity by promoting unhealthy foods. They indicate that bad eating habits formed during childhood can persist throughout life [15]. TV advertising influences children's product consumption, yet little is known of its influences on Kenyan children.

At present there are no laws governing advertising in Kenya, as a result there is no legal control over TV advertising to children. In order to help children enjoy their rights - which include the right to information of good quality, freedom of expression, participation in media and, protection from harmful media content there should be a legal control on TV advertising content. All stakeholders must share responsibility in ensuring children are protected against harmful media. The main players in this endeavour are policy makers, teachers, parents, media professionals and organizations concerned with children. The rationale for the study arose from the fact that there has been little research done in this area on the impact of TV advertising on children in Kenya.

\section{Materials And Methods}

This was the case with the study conducted in Buruburu estate in Nairobi Kenya. There are quite a number of middle class estates in Nairobi, making it difficult for the researcher to study children from every middle class estate because of their large number. Many estates have large numbers of children who are considered middle class. For the purpose of collecting data, the author selected Buruburu estate because it is one of the oldest middle-class estates whose residents show general characteristics associated with the class. It is also the oldest middle-class estate as classified by Nairobi City Council and the biggest single housing scheme in Kenya with same house design [16].

The model of survey research was used in answering research questions. Survey research involves selecting a sample and administering a questionnaire or interview guide on them. Survey design instruments have the ability to measure attitudes and orientations in a large population. This design was appropriate for the study because it planned to use individuals as its unit of analysis, i.e. children and parents.

The sample population comprised children aged between 6 and 13 years, exposed to TV advertising. A total of 70 children from Buruburu estate were interviewed. Thirty-five children in the sample were between ages 6 and 9 years while the remaining thirty-five were between 10-13 years. The sampling method used in selecting samples for interviews was the stratified random sampling technique. Maniscalo [17] indicates that children begin to pay attention to TV adverts as early as 12 months of age. It is not until they are between 2-3 years of age that they begin requesting for products. At around 3-4 years of age they can make choices as their 
TV viewing time increases thus exposing them to a lot of product advertising. By ages 5-6 years, most children have developed the "art of persuasion" and can be quite successful in influencing parents into purchasing advertised products. However it is around the age of 9 or older that children develop the ability to think critically about their choices and view television advertisements with a critical eye. Ability to differentiate 'reality' from fantasy increases with age.

Two techniques of discussions were used to source data from the respondents. They included the use of interview guides and focus group discussions as a supporting method. Interview guides were used to collect data while the focus group discussions were used to verify the collected data. Primary data collection was done within three weeks while the weeks that followed were allocated to data coding and analysis. Secondary data was gathered through library research, which included published and unpublished works. These were textbooks, journals, reports, Acts of Parliament, discussions with experts, internet and dailies, among other relevant sources.

Data from the field was coded carefully to ensure a high degree of accuracy and consistency. Coding was followed by frequency counts of data from which tables and other graphic representations were generated. The interview guides were coded before content analysis begun. A report was then done to summarize data from the interviews and focus group discussions. Data from the interview guides were later presented in tables and graphs in the form of percentages and frequencies. Where necessary, mean scores were obtained to give an average view of variable measured. Content analysis of data was done in order to make an objective judgment of facts and opinions. The data was analysed in terms of their age groups and that was also the format used in presenting the findings. All this resulted in the formation of learned opinions on the topic of study.

\section{Results And Discussion}

Parent's opinions were sought to ascertain the extent to which they took part in understanding and interpreting advertisements directed at children in their families. Among the parents/guardians interviewed $90 \%$ of them were females while $10 \%$ were males. The sample group was composed as follows: $36.67 \%$ was made up of business people ( $6 \%$ were men), $13.3 \%$ were teachers, $16.67 \%$ were house-wives, $10 \%$ were office secretaries, $3 \%$ were researchers (all were male), $6 \%$ were nurses, $3 \%$ were marketers, chefs and bankers.

On average parents watched 36 hours of television a week, 3.6 hours during weekdays and 9 hrs during weekends. This closely compares with findings by Mwakesi [18] that middle class adults were spending 30 hours on the TV viewing per week. Possibly, the hours have increased over the years with the development of the TV industry, since there are more TV stations offering a variety of channels and therefore a wider and better option of programmes for the viewers.

A greater percentage of this middle-class group are in professions, implying that they have a high level of education. Their values therefore are set to be inclined towards aspiring to be like people in the high-class group. They want to own valued assets, lead admired lifestyles and therefore inculcate these values in their children. It is not surprising therefore that they are a big target for advertisers who promise to offer them just the kind of life they admire. It was also notable that it is easier to find more females (90\%) than males at home over the weekends. This was because most males preferred to spend time in places like bars with friends, going out to watch sports, work, visiting friends and relatives and involving in other outdoor activities.

\subsection{Parents discussing TV Adverts with Children}

When parents/guardians were asked why they sometimes discussed TV advertising with their children they responded as follows: Some parents said there were adverts that portray undesired values and behaviour and in order that their children to get to know that the behaviour/values are not worth emulating, they discussed such adverts when they were aired. Parents said they discussed adverts they thought had something interesting, which they felt children could benefit from. Some parents discussed TV adverts only when their children prompted them to, by asking questions.

Those parents that did not discuss TV advertising with their children said it was because of the following reasons: they did not find it important and felt it did not make a difference in the child's life. Others were of the opinion that since all advertising targets adults there is no need to discuss it with children. Others felt that sometimes TV advertising is too embarrassing to be discussed with children.

\subsection{Bad Influence of TV Adverts}

Parents expressed the following discomforts about some TV adverts, especially when children watched: $66.67 \%$ said there were adverts they felt were bad and were not suitable for children's viewing. The remaining $33 \%$ did not think the same, and were therefore not against any TV adverts when it came to children. Some to the TV adverts they were strongly against included those of 'Trust' Condoms, Anti-AIDS campaign, 'Beers'(One that has an ending slogan that reads 'Unapokunywa zaidi ndivyo unavyoteleza zaidi' [the more you drink alcohol the more you slide referring to ones reasoning capacity after taking alcohol]) and 'BambuaTafrija' 
beer competition, and 'Fresh-Fri' cooking oil. Some of their reasons for being against the TV adverts were as indicated below.

'Bambuatafrija' advert, according to the parents, may lead children to venture in inappropriate places such as pubs unaccompanied, to collect bottle tops needed for the competition. This could endanger their safety. The MSK code of ethics No. 21.2.3, on children, and safety, advises against adverts that 'encourage children to enter strange places or to converse with strangers in an effort to collect coupons, wrappers, labels or the like.'

On being asked to state their reasons for their discomfort with some of the TV adverts, the parents gave their responses as shown in Table 1 below.

Table 1: Reasons for Discomfort with Certain TV Adverts

\begin{tabular}{l}
\hline Reason \\
\hline a) The demonstration on how to use a condom is vivid and so exposes a young mind to some issues too early \\
b) Some ads make children ask unexpectedly embarrassing questions \\
c) Beer TV ads are presented in a way as to attract young people making them feel drinking is alright and has no \\
consequences \\
d) Some adverts teach reversed roles where a woman goes to work and the husband remains doing the housework \\
(Fresh fri oil) \\
e) Sanitary towels are a private issue which should not be exposed on screens especially during meal times (it is \\
disgusting) \\
f) Some AIDS campaign ads present such indecent scenes that instead of warning people it entices them to the very \\
danger
\end{tabular}

Television advertising has a moral attachment that cannot be ignored, especially when it comes to targeting children. The table above expresses parents' sentiments on TV adverts they felt impacted negatively on their children's morals and values. These adverts do not adhere to the MSK code, which stipulates that alcohol adverts should not suggest sexual indulgence or permissiveness (code No. 3.6). This should apply to other products as well since they seem to fall under the same category

\subsection{Change of Products and TV Adverts}

The study also sought to ascertain the impact of TV advertisements on the change of products in the families. The parents gave the motivations for the change of products as shown in Table 2 below.

Table 2: Motivations for Change of Products

\begin{tabular}{ll}
\hline Reason & $\%$ \\
\hline a) Just to please the child & 43.33 \\
b) When children nag too much & 16.67 \\
c) To satisfy the child's as well as my own curiosity about the product & 20 \\
\hline
\end{tabular}

Some parents said that they did change products based on the requests of their children for the following reasons: first was to please the child (43\%), when the children nagged and pestered them too much (16.67\%) and to satisfy the children's curiosity as well as theirs mentioned by $20 \%$. Reasons (a) and (b) suggest that parents are slowly losing control on decision-making. This is because they bow to children's demand for TV advertised products, and are easily succumbing to their naggings. Some parents felt that they should be able to guide their children on what is good for them and not be dictated to by children. Children's pressure resulting from TV advertising should not dictate to parents on what to buy.

\subsection{TV Advertising and Family Budget}

In relation to the change of products discussed above, the study also sought to find out if TV adverts directed at children affected the family budget. As such, parents were asked to state whether or not children's requests were usually in line with family's budget, and response were as follows: $43 \%$ said it fitted within their budgets while $23 \%$ said it did not. The data suggests that TV advertising causes children to pressurize parents to buy products outside the family budget. Parents were forced to buy advertised products possibly fearing negative reactions from their children, which were as expressed in the table below.

\subsection{Resulting Behaviour}

The parents were also asked to state any changes in behaviour of their children as a result of advertisements.

Table 3: Resulting Behaviour of Parents

\begin{tabular}{ll}
\hline Behaviour & $\%$ \\
\hline a) Understanding, showing no negative emotions & 33.33 \\
b) They get annoyed, sulk and are rude for a while & 53.33 \\
c) Throw tantrums and cry & 13.33 \\
d) They feel that parents are deliberately denying them & 3.33 \\
\hline
\end{tabular}


When children's requests were not met, parents said children expressed their emotions as indicated below: $33 \%$ of the parents mentioned that their children were understanding and so did not show any negative emotions. 53.33\% mentioned that the children would get annoyed, sulk and be rude for a while, $13 \%$ said they would cry and throw tantrums. 3.33\% said that their children felt that they were deliberately denying them 'pleasure' yet they had money to buy them the advertised product. This suggests that TV advertising may cause children to mistrust their parents. This may cause a strain in the parent-child relationship.

\subsection{Request for Inappropriate TV Advertised Products}

Parents were asked if their children ever asked for TV advertised product that they felt were inappropriate for them. Their responses were: $60 \%$ said yes while $40 \%$ said no. Examples of advertised products requested for which parents felt were inappropriate were like medicine, skin toning creams, and mobile phones. This concurs with earlier findings that indicate that TV advertising encourages children to ask for inappropriate products.

Parents' responses on how they felt TV advertising was negatively influencing their children confirmed some of the earlier findings. Ten per cent felt that it negatively influenced children's morals but could not give evidence for it; $10 \%$ said that it promoted the value of consumerism/materialism among children; $13.33 \%$ mentioned that some adverts positively informed children on sexual issues. Such issues included vividly warning them against HIV/AIDS in a manner that parents would not do. Adverts also negatively informed children on some sensitive sexual issues when still too young.

Of the parents, $23.33 \%$ felt that TV advertising made their children pester and nag a lot for unnecessary things; $20 \%$ said it contributed to unnecessary arguments with parents especially when a request was denied. Before children accepted what was availed to them, but with the coming of TV adverts they have attached price tags to certain products and demand them until they are bought. Some felt that TV advertising was making children more selfish and individualistic in that they only think of themselves and, 'I want' has become their language.

\subsection{TV Advertising and Values}

Parents felt that TV advertising is promoting the following values: $33.33 \%$ felt it promoted African values while $66.67 \%$ felt it promoted western values. Parents preferred values as indicated: $60 \%$ advocated that TV advertising should promote African values, $10 \%$ opted for Western values while $30 \%$ advocated for a balance between the two. Some of their reasons for choosing values as indicated were: since they were Africans they felt their children should learn African values so as to identify with them. These parents felt that African values were less permissive and so would less influence their children negatively.

Some of the negative values parents mentioned included materialism that was more of a western value, and it is promoted so much by TV advertising. Materialism instils in the target audience the idea that owning material things can bring about happiness. Secondly some parents thought western values encourage individualism, where one strives to acquire things for themselves and communal participation is no longer encouraged valued. This in turns promotes the value of selfishness, which was not encouraged in an African set up.

Other parents felt that because the world is changing, children needed to be at par with the rest of the world. This is because western countries seem to set the standard for the rest of the world. Those who were for a balance between the two values said that there was something valuable in both.

\subsection{Parent's Suggestion on Control of TV Advertising}

Parents were not aware of any regulations governing advertising. They instead made the following suggestions on ways of minimizing the negative impacts of TV advertising to children. The suggestions were divided into two as shown below:

\subsubsection{Showing Times}

a) There should be a specific showing time for certain adverts, and this be done within adult programming.

b) Advertisements targeting adults should be aired late in the night when children are supposedly asleep.

\subsubsection{Type of Advert}

a) Some parents felt that all the TV advertisements were all right and that there was nothing wrong with them.

b) Alcohol adverts should be totally banned from TV and be advertised in places like pubs where they are consumed. 
c) Advertisements for products such as condoms be banned from TV and use other media to advertise such as; print. Parents argued that this would work because children do not get to interact with print a lot compared to television.

d) Cartoons should not be used to advertise products inappropriate for children e.g. alcohol or cigarettes.

e) Television should do much more of social marketing/rather than commercial advertising.

f) Older models should be used in advertising certain products to prevent children from wanting to associate with models in the advert. This is especially so for adult products such as alcohol.

g) A warning should accompany every television advert that is strictly targeting adult audience. This is so that children may know first-hand that the product is inappropriate for them.

\section{Conclusion And Recommendations}

The study findings have shown that middle-class parents in Buruburu are generally aware of the harms that TV advertising could have on their children. Indeed, parents should begin to take an active role in enlightening their children on adverts. This would help minimise some of the possible negative influences by making children understand the purpose and intentions of adverts. Although TV advertising has negative influence it does have a beneficial side for example it gives information on a product and demonstrates its use. The positive side of TV advertising on children was not discussed in the report because it was beyond the scope of this study.

To enhance parental - adult - involvement on issues regarding advertising to children, it is recommended that parents and teachers need to start discussing TV adverts with children so as to educate them on intents and truth elements in them, among others. Primarily, responsibility lies with the parents over which TV adverts their children watch. They should be able to control what their children watch, though the government should assist in this through controlling TV stations advertising content. In addition, there is need for the government to set policies governing advertising which will specifically address children as a vulnerable group. A bigger sample population including children from the different social classes should also be studied to yield more information on children and TV advertising.

Moreover, cartoons should not be used to advertise products inappropriate for children, e.g. alcohol or cigarettes. In general, advertising policies should stress social marketing rather than commercial advertising on television. As such, CCK or KFCB should review adverts before they are run, and give advance clearance in an advisory capacity. On their part, researchers and the society should tighten rules on self-regulation, and help the government make better-informed decisions. For instance MSK can work closely with the government to offer professional advice concerning advertising. Apart from that, EKFCB, which currently classifies films, should be empowered to do the same with advertising. Possibly advertisements should be rated in the same way films are classified (This is done according to the dangers they pose to minors, based on general and scientific-founded principles). Above all things, a legal framework for classifying advertising should be developed in Kenya.

\section{References}

[1] W. F. Arens and C. F. Bovee. Contemporary Advertising. Sydney Australia: Irwin Publishers, 1994.

[2] D. Ingman. Television Advertising. London: Business Publications Limited, 1970.

[3] Marketing Society of Kenya (MSK), 2005

[4] M. Ogutu. "Advertising Agencies in Kenya: Their nature and operations", M.A. Thesis. University of Nairobi, 1983.

[5] T. Mutiso. "Evaluation of the Relationship between Advertising and the Media house in Kenya", MA Thesis, University of Nairobi, 1989.

[6] Weekly Review (1983). Why Nairobi Times had to go (Hillary Ngweno).

[7] J. Dominic. The dynamics of Mass communication. New York: McGraw Hills Company, 1990.

[8] F. Jefkins. Advertising. London: Pitman Publishers, 1994.

[9] The East African (2003, November).

[10] G. Belch. Introduction to advertising and promotional Management. Von Hoffman Press, 1990.

[11] Kariuki, J. (2001, July 9). Kenya moves to limit foreign presence in TV. East Africa Weekly. Nairobi: Nation Publishers.

[12] United Nations in Cooperation with the Kenyan Government (1996). Convention on the Rights of the Child. United Nations Department of Public Information.

[13] Carlson and Feilitezen (1998)

[14] C. Feilitzen and C. Bucht. Outlook on Children and Media. UNESCO International Clearing House on Children, Sweden, 2001.

[15] M. Dittmann. "Protecting children from Advertising". Monitor Magazine, vol. 35, p 58, 2004.

[16] J. B. Morgan. "Rent control in Middleclass Housing: A case study of Buruburu Estate Nairobi" M.A thesis, University of Nairobi, Kenya, 1985.

[17] Maniscalo (1993)

[18] I. Mwakesi. "Television viewing habits of adults in Nairobi”, Project in Postgraduate Diploma, University of Nairobi, 1989. 